\title{
FiM DA LUTA DE CLASSES? \\ A teoria das Classes em Poder POLÍTICO E CLASSES SOCIAIS A PARTIR de Maio de 1968 E SUA PECULIARIDADE EM RELAÇÃO À CORRENTE ALTHUSSERIANA ${ }^{1}$
}

\author{
Andriei Gutierrez ${ }^{2}$
}

\begin{abstract}
RESUMO
Partindo de algumas interpretações sociológicas suscitadas pelo Maio de 1968, 0 artigo pretende resgatar a centralidade da teoria das classes sociais para 0 entendimento dos diferentes movimentos sociais e organizações coletivas. Para tanto, apóia-se nas contribuições da obra Poder político e classes sociais, de Nicos Poulantzas, procurando estabelecer quais são as suas peculiaridades, avanços e
\end{abstract}

\footnotetext{
${ }^{1}$ Agradecemos as observações críticas de Danilo Enrico Martuscelli, Leandro Galastri e Lúcio Flávio de Almeida às versões preliminares deste artigo. Gostaríamos de mencionar diretamente a influência das discussões teóricas sobre classes travadas no interior do Grupo de Pesquisa de Teoria das Classes Sociais (do Centro de Estudos Marxistas da Unicamp) neste trabalho. Também é necessário ressaltar as contribuições das discussões coletivas sobre classes e movimentos sociais, travadas pelo Grupo de Pesquisa sobre Neoliberalismo e Relações de Classes, também do CemarxUnicamp, que ajudaram especificamente na construção da primeira parte do texto.

${ }_{2}^{2}$ Doutorando em Ciência Política pela Unicamp. Email: andriei.gutierrez@uol.com.br
} 
limites em relação ao processo de renovação do marxismo, de um modo geral, e, particularmente, no interior da corrente althusseriana. A tese geral é de que há nessa obra uma teoria das classes sociais presente em estado prático, cuja principal característica é o primado das práticas sociais na delimitação das classes sociais. Palavras-chave: Marxismo. Nicos Poulantzas. Classes sociais. Althusserianismo.

\begin{abstract}
s
Departing from sociological interpretations inspired by May of 1968, this article attempts to revive the centrality of the theory of social classes for the understanding of the different social movements and collective organizations. To that end, it departs from the contributions of Nicos Poulantzas's Political Power and Social Classes, attempting to determine its peculiarities, advances and limits en relation to the process of renovation of Marxism, in general, and the Althusserian current, in particular. The general thesis is that this work has a theory of social classes in a practical state, whose principle characteristic is the primacy of social practices in the delimitation of social classes.

Keywords: Marxism. Nicos Poulantzas. Social classes. Althusserianism.
\end{abstract}

\title{
Acerca da Centralidade das Classes Sociais
}

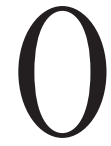
s eventos consagrados no notório Maio de 1968 têm lugar destacado nos estudos em ciências sociais: consolidam toda uma etapa de construções teóricas na qual se passa a questionar a validade das interpretações das lutas sociais centradas nas classes sociais. Coincidentemente, 1968 também é o ano em que Nicos Poulantzas publica Poder político e classes sociais, que, dentro de um processo mais amplo de renovação do marxismo, reafirmava a centralidade das classes sociais para o entendimento das diferentes organizações sociais e ações coletivas.

Até o início do século XX, tanto as análises com inspirações marxistas quanto weberianas, embora se distinguissem frontalmente em suas teorias das classes, tinham um ponto de aproximação no que diz respeito à delimitação das classes sociais nas formações sociais do período: de um modo geral, a classe operária era identificada aos trabalhadores manuais, particularmente ao operário 
industrial, e a burguesia, por sua vez, associada à posse de propriedades. ${ }^{3}$ As análises sociológicas das diferentes formações capitalistas, por sua vez, tendiam a partir do conflito entre essas duas classes como sendo a instância central das lutas sociais. Grosso modo, pode-se dizer que a idéia de "luta de classes" assumia, no final do século XIX, uma centralidade histórica para ambas as teorias - e, ao mesmo tempo, uma centralidade teórica para a teoria marxista. Com a complexificação da estrutura de classes e a criação de novas ocupações intermediárias levadas a cabo pelas alterações do novo tipo de desenvolvimento capitalista da primeira metade do século XX, algumas análises sociológicas de inspiração weberiana começam a questionar essa centralidade histórica e anunciam o surgimento de outra classe, um novo ator social: a "nova classe média" (MILLS, 1979; LOCKWOOD, 1962)․․ Essa classe média - ou trabalhadores de colarinho branco -, na sua versão mais popular de Wright Mills (1979), tinha como característica uma indiferença política e uma posição social estratificada a partir da sua situação de trabalho, que era marcada por um status, uma renda e um prestígio diferenciados das posições de classe da classe operária e da burguesia. Por outro lado, em setores influentes da teoria marxista, associava-se os trabalhadores assalariados não-operários a uma concepção ampliada de proletariado devido à característica comum de assalariamento e justificava-lhe a apatia política por uma ausência de "consciência de classe" (RUMIANTSEV, 1963). Considerando ambas as linhas de interpretação, não seria incorreto dizer que os acontecimentos de Maio de 1968 teriam pegado de surpresa grande parte das análises sociológicas em voga no período. Como explicar o surgimento de um movimento político não-operário reivindicativo de tal envergadura como o que surgia na cena política naquele período?

É neste sentido que se pode dizer, grosso modo, que Maio de 1968 inspirou uma significativa reformulação das análises sociológicas principalmente no que diz respeito ao estudo das diferentes organizações sociais e ações coletivas. Não é a pretensão deste artigo fazer um balanço geral de todas as interpretações sobre o Maio de 1968, muito menos expor todas as correntes sociológicas acerca dos chamados "novos movimentos sociais". Apenas pretendemos pontuar, a título

\footnotetext{
${ }^{3}$ É preciso atentar para o fato de que o conceito de "classe social" não é o mesmo para Marx e Weber. Enquanto para este último classe social é a posição dos indivíduos no mercado, processo de distribuição - e aqui se segue por pressuposto a aceitação da teoria do valor ricardiana -, para Marx a classe social é definida a partir da posição que os agentes ocupam no modo de produção, por relaç̧ões de exploração específicas. Sobre o tema, ler Hirano (1973).

${ }^{4}$ As edições originais de Mills e Lockwood datam de 1951 e 1958, respectivamente.
} 
introdutório, aquelas interpretações que consideramos as mais significativas, assim como aquelas que hoje em dia parecem ganhar maior destaque na academia brasileira.

Maio de 1968 ficou conhecido, segundo a bibliografia, como uma expressão subjetiva da luta contra todas as formas de alienação - material, estética e moral: as lutas que se travaram nesse período seriam marcadas pela crítica às "burocracias totalitárias" do leste europeu e à "sociedade do espetáculo" do mundo capitalista em busca da reafirmação individual, da própria "essência humana" (MATOS, 1999). Parte da literatura sociológica interpretaria esse acontecimento como sendo uma expressão da emergência de um novo tipo de sociedade, uma sociedade diferente daquela estudada por Marx e Weber: a alteração dos tipos de organizações sociais e de ações coletivas não teria só a ver com a modificação dos atores sociais, mas sim com uma possível mudança estrutural da própria sociedade, no sentido de uma "sociedade pós-industrial". Na versão mais ortodoxa dessa teoria, o saber abstrato da ciência e dos cientistas teria substituído os saberes concretos da produção e, conseqüentemente, os engenheiros ocupariam cada vez mais o lugar dos operários (BELL, 1977). Diferentemente, para a versão menos ortodoxa - e a que mais nos interessa-, na sociedade pós-industrial a indústria continuaria tendo um papel central no desenvolvimento econômico, assim como a classe operária não perderia sua importância (TOURAINE, 1971, p. 18); mas, viveríamos num outro tipo de sociedade na qual o desenvolvimento seria pautado mais diretamente do que antes no conhecimento, o que possibilitaria a expansão da dominação social para outras formas além da exploração econômica: 1) a integração social dos atores no consumo e nas estruturas de trabalho a partir da ampliação de ocupações profissionais sobre um sistema de produção centralizado e controlado; 2) a manipulação cultural; e 3) a dominação por grandes organizações ao mesmo tempo econômicas e políticas. Dessa perspectiva, a emergência de conflitos e lutas sociais estaria ligada mais à luta contra a alienação em busca da criatividade e da liberdade do que de contra a exploração; os valores culturais assumiriam um elemento central de unidade da identidade dos grupos marginais que tomariam consciência de sua dependência e agiriam no sentido de sua autodeterminação (TOURAINE, 1971, p. 11).

Para parte significativa da bibliografia recente sobre os chamados novos movimentos sociais, surgida a partir dos anos 1990, as lutas "moralmente motivadas" de grupos sociais, lutas difusas por reconhecimento das diferenças, corresponderiam não a um período histórico específico, mas a uma espécie de 
motor da história evolutiva da espécie humana. Os movimentos organizados de defesa do meio ambiente, dos direitos das mulheres, étnicos, das minorias, etc., estariam ligados, dessa maneira, a uma teoria antropológica específica. A validade da análise centrada na luta pelo reconhecimento se basearia na suposição de que a reprodução da vida social se efetua sob o "imperativo de um reconhecimento recíproco dos sujeitos" que, no âmbito da história, operaria como uma espécie de "[...] coerção normativa obrigando os indivíduos à deslimitação gradual do conteúdo do reconhecimento recíproco [...]" rumo a uma "ampliação simultânea das relaçõesde reconhecimento mútuo" (HONNETH, 2003,p. 155-156).Osdiferentes tipos de lutas moralmente motivadas de grupos sociais pelo estabelecimento de formas de reconhecimento mútuo cultural e institucionalmente teria como resultado final, a capacidade de conduzir a uma sociedade emancipada.

Enquanto as teorias da sociologia da estratificação social dos anos 1950 procuravam justificar o fim da centralidade histórica das classes sociais nas lutas sociais por meio do surgimento de um novo ator social, as teorias sociológicas que emergiram após o Maio de 1968 procuraram fornecer uma análise teórica que jogasse por terra qualquer possibilidade de centralidade teórica das classes sociais para o entendimento das diferentes organizações sociais e ações coletivas, assim como também para explicar os diferentes tipos de conflitos sociais. 0 modelo de Honneth parece ser mais frágil, uma vez que está presente no conceito de reconhecimento uma espécie de determinismo evolucionista da idéia de "conflito" orientado por uma concepção ideal de indivíduo e de igualdade social. Mesmo elevado ao estatuto de axioma - pedra angular de construção de uma teoria científica -, ao se analisar a sua consistência lógica, esse conceito ideal de sujeito e de igualdade social não se sustenta à luz das diferentes sociedades humanas historicamente conhecidas, reduzindo-se a sua validade axiomática a apenas um período histórico da humanidade, caracterizado pela concepção moderna de sujeito que é inaugurada pelo tipo de Estado capitalista e o formalismo jurídico que lhe é característico (que estabelece como "iguais" juridicamente os "desiguais" nas diferentes esferas econômicas e de distribuição de poder). Por sua vez, o modelo teórico apresentado por Touraine tem a vantagem de ter uma abrangente aplicabilidade prática, na medida em que a lógica que dá unidade a determinado grupo social e às diferentes ações coletivas diz respeito a uma identidade cultural própria em relação a uma gama de possíveis variáveis históricas de dominação social. Mesmo a despeito de sua capacidade descritiva, é necessário, no entanto, apontar os limites dessa interpretação teórica no que diz respeito à possibilidade de 
previsão histórica, no sentido de ser capaz de antecipar-se às possíveis tendências sociais de transição de um tipo de organização político-social a outro.

Recentemente surgiu, no cenário acadêmico, uma abordagem teórica que almeja conciliar a "luta pelo reconhecimento" com o conceito de classe social e, assim, dar conta de explicar as possíveis transições. Nancy Fraser (2001) defende que, apesar de as "identidades grupais" - que, segundo ela, orientam e dão unidade a determinado movimento organizado - terem substituído os interesses de classe, isso não inviabilizaria a possibilidade de uma interseção entre "raça", gênero, sexualidade e classe - entendida como o lugar na economia -, que poderia explicar a emergência de "soluções transformativas" da estrutura social. Apesar de a autora afirmar que a separação entre o que ela entende por "injustiça sócio-econômica" e "injustiça cultural" (fontes de descontentamento seja das classes seja dos diferentes movimentos sociais, respectivamente) seriam de ordem analítica e na prática estariam interligadas (p. 251), permanece uma incompatibilidade teórica entre os conceitos de classe e de reconhecimento, uma vez que é feita - no nível da análise - uma separação não bierarquizada entre as práticas reivindicativas dos diferentes grupos sociais e as práticas propriamente de classe, estas últimas entendidas como as forças motrizes da transição de uma organização político-social a outra. Mesmo a despeito da intenção de potencializar a capacidade explicativa da teoria a partir da inserção do conceito de classe social, a problemática de fundo da autora permanece a mesma de Honneth, no sentido em que ela adota uma idéia fixa de justiça cuja finalidade seria o reconhecimento mútuo e, por conseguinte, estaria amparada em um conceito ideal de indivíduo e de igualdade.

Aliás, antes de avançarmos para a análise de Poder Político e Classes Sociais, é necessário fazer uma ponderação. A academia é marcada hoje por um senso comum que identifica todas as tentativas marxistas de explicar a sociedade e as ações coletivas sustentadas na teoria das classes sociais a uma abordagem "produtivista", ou que só levaria em conta as contradições econômicas na definição das classes e subordinaria, de maneira quase que mecânica, as dimensões simbólicas e culturais de dominação ao elemento econômico.

Não seria demasiado errôneo identificar a origem dessa concepção no predomínio histórico de um tipo de abordagem hegemônica do marxismo, que tendeu a identificar classe social ao exato posicionamento dos agentes no modo de produção, classe em si, e a ausência de uma luta efetiva da classe dominada a 
partir da idéia de inexistência de uma consciência de classe para si. Esse tipo de abordagem, fortemente influenciada pela dialética hegeliana e por sua herança presente nos textos de juventude de Marx, apoiava-se, grosso modo, na premissa de que toda sociedade em sua aparência seria o reflexo de uma essência escondida e determinante: a economia constituir-se-ia na estrutura sob a qual se desdobrariam, como epifenômeno, a política e a ideologia.

Sob essas condições, somos obrigados a reconhecer a justeza das críticas a um tipo de marxismo que se constitui como um sistema analítico marcado por uma determinação econômica de tal envergadura que não daria conta das esferas culturais e simbólicas que influenciam as práticas sociais por meio das noções de "identidade", "dominação cultural" e até - nos marcos ideológicos do Estado Capitalistaedoformalismo jurídico quelheécaracterístico - "reconhecimento". No entanto, acreditamos poder haver outra leitura possível no interior da problemática marxista que contemple o problema assinalado. A idéia de existência de uma determinação em última instância da economia sobre as outras esferas da vida social, sugerida por Louis Althusser, significa um grande passo nesse sentido. E isso porque, partindo dessa concepção, a determinação econômica não precisaria ser arbitrária sobre as diferentes determinações de ordem cultural ou simbólica. É neste sentido que segue a intenção abaixo ao analisar Poder político e classes sociais; pretende-se retomar a leitura da referida obra, procurando evidenciar alguns elementos presentes que ajudam a enunciar os marcos de uma teoria das classes sociais que possibilite o entendimento das ações coletivas e dos movimentos organizados, procurando entender os diferentes conflitos da sociedade capitalista como também prever as possibilidades de transformações - e até superações - das formações sociais capitalistas.

\section{Poder Político e Classes Sociais e o Processo DE RENOVAÇÃO do MARXISMO: A INFLUÊNCIA DA ESCOLA ALTHUSSERIANA}

A leitura das obras de Marx feita pela chamada "corrente althusseriana" distingue-se da leitura predominante do marxismo do século XX por defender a

\footnotetext{
${ }^{5}$ Em referência ao grupo de estudiosos que visavam contribuir para o processo de renovação do marxismo, dentre eles Louis Althusser, Étienne Balibar, Alain Badiou, Charles Bettelheim, o próprio Nicos Poulantzas, entre outros.
} 
existência de uma ruptura de Marx com a dialética hegeliana. Marx não teria simplesmente invertido a dialética hegeliana separando-a da filosofia especulativa e aplicado-a ao mundo real. Em suas obras de maturidade, como 0 Capital e nas suas obras políticas, Marx teria subvertido - embora sem enunciar - a própria noção de dialética. Althusser (1974, p. 81) afirma que,

[...] a 'contradição' [ele usa o termo entre aspas para indicar a "unidade das contradições"] é inseparável da estrutura do corpo social inteiro, no qual ela atua, é inseparável das condições formais de sua existência e das mesmas instâncias que governa; ela mesma é afetada, no mais profundo do seu ser, pelas ditas instâncias, determinante mas também determinada em um só e mesmo movimento, e determinada pelos diversos níveis, e pelas diversas instâncias da formação social que ela anima; poderíamos dizer: sobre determinada em seu princípio. (grifos do autor)

Recusa-se, dessa maneira, a leitura hegemônica do marxismo de que haveria uma distinção entre "estrutura" (economia) e "superestrutura" (política e ideologia), fundamentada no primado do elemento econômico como forma de entendimento das sociedades de classes. A corrente althusseriana procurou trabalhar a relação entre economia e sociedade de um novo modo: por meio da correlação entre "determinação em última instância" e "instância dominante"; a sociedade deixaria de ser um epifenômeno direto da economia e o conceito de modo de produção passaria a abarcar também a possibilidade de dominação das instâncias política e ideológica. A determinação do elemento econômico ocorreria apenas em última instância (ALTHUSSER, BALIBAR, 1971; ALTHUSSER, 1974).

No entanto, é preciso também atentar para os limites que acompanham essa nova leitura do marxismo. Como mostra Saes (1994, p. 46),

[...] a corrente althusseriana só opera, no trabalho teórico sobre os diferentes modos de produção (que é, sublinhemos bem, análise do funcionamento reprodutivo do "todo" social), com a idéia de "implicação recíproca" das instâncias [econômica, política e ideológica]; os conceitos de "determinação em última instância" e de "dominância" se mantêm, estritamente, como elementos do conceito de modo de produção em geral. Isso equivale a dizer que tais conceitos, na medida em que se revelam incapazes de "descer" ao terreno da teoria dos modos de produção particulares (feudal, capitalista, etc.), são inoperacionalizáveis (grifos do autor).

Assim, esse deslocamento da determinação do econômico para um nível teórico mais geral quando aplicado ao nível do modo de produção particular seria 
apenas uma versão "oficial" que em sua aplicação prática, por Althusser e Balibar (1971), corresponderia a uma "implicação recíproca" das instâncias da totalidade social. 0 resultado seria uma incompatibilidade teórica entre os conceitos de "determinação em última instância" e "dominância" e a idéia de "implicação recíproca".

Devido ao fato de Poulantzas ter muita proximidade com os estudos dessa escola - o que permite também incluí-lo nela -, é comum vermos as críticas à leitura althusseriana do marxismo serem transpostas para a obra Poder político e classes sociais. Grosso modo, defende-se que os trabalhos da escola althusseriana, em geral, teriam sistematizado uma base teórica do conceito de materialismo histórico - e de modo de produção - sob a qual Poulantzas, por sua vez, fundaria uma "metodologia de análise das classes sociais e do Estado" a partir da possibilidade de constituição de "teorias regionais" do econômico, do político e do ideológico (CARDOSO, 1973; LÉGER, 1976). Cabe observar que essa tese é respaldada pela própria obra de Poulantzas, pois não há em seu trabalho uma formulação explícita no sentido de se distanciar do modo pelo qual a corrente althusseriana trabalhava a relação entre os diferentes níveis da análise teórica. ${ }^{6}$

Defendemos que Poulantzas retém, principalmente, da escola althusseriana o modo como ela trabalha a relação entre teoria e prática, que é materializado na leitura estrutural que a corrente faz do marxismo. Fortemente influenciada pelos escritos de Mao Zedong, a principal contribuição dessa leitura "estrutural" será propor uma nova forma de trabalhar a relação entre teoria e prática, resgatando a concepção do primado da prática: todo exercício teórico seria, assim, uma prática social e historicamente determinada e, como tal, poderia sofrer diversas limitações e vicissitudes do seu contexto político-ideológico; toda produção de

\footnotetext{
${ }^{6}$ Sob esta perspectiva, também se encaixaria a crítica de Saes (1998) a Poder político e classes sociais. Para ele, há uma importante diferença entre as aplicações feitas por Poulantzas e pelo conjunto da corrente althusseriana (especificamente, Althusser, Badiou e Balibar) da concepção da autonomia relativa das instâncias do modo de produção. Saes afirma que Poulantzas "[...] parece inverter o raciocínio dos althusserianos, apresentando a possibilidade de fixar as estruturas do modo de produção como objetos teóricos independentes, e, portanto de conceituá-las, como decorrência da autonomia real das instâncias na prática social total"; enquanto que "[...] a sua matriz 'prática' do modo de produção, em operação nas análises que compõem Poder político e classes sociais, é aquela que aponta a implicação recíproca - ou interdependência - das estruturas econômicas e jurídico-política [...]”. Isto caracterizaria, para Saes (1998, p. 55-56), uma contradição que seria "[...] a conciliação teórica entre as idéias de autonomia e de interdependência, quando ambas são encaradas como características reais do relacionamento entre os níveis da prática social total".
} 
teoria inevitavelmente estaria sob influência das ideologias de sua época e seria preciso, pois, um cuidado especial na análise e manipulação - a posteriori - dos conhecimentos. A esse processo de produção de conhecimento feito pela prática humana, Althusser dá o nome de "prática teórica". Quando aplicada ao conjunto das obras de Marx, seria constatado que a própria produção teórica de Marx também estaria sujeita, como prática teórica que era, a esse tipo de limitações e deveria ser interpretada de modo crítico, por uma "leitura sintomal" (ALTHUSSER, 1974). Poulantzas, ao propor a possibilidade de uma teoria regional do materialismo histórico, estabelece uma relação entre estruturas e práticas na qual há um primado das práticas sobre os conceitos teóricos, identificados nas estruturas. ${ }^{8}$

Ainda antes de adentrar na análise da obra de Poulantzas, resta afirmar que é possível extrair dela uma formulação teórica em estado prático, que marca um avanço e, em certo sentido, uma ruptura com algumas das teses presentes na escola althusseriana. Seguramente, como insistem os críticos, ${ }^{9}$ Poulantzas introduz uma nova metodologia de análise das classes sociais e do Estado associada à possibilidade de existência das teorias regionais. Mas isso é feito ao preço de uma nova hierarquização entre os níveis da análise teórica, refletida em uma relocalização da determinação em última instância do elemento econômico na articulação do sistema conceitual. Defendemos, assim, que existe em Poder político e classes sociais uma teoria das classes em estado prático - amparada em leituras das obras políticas de Marx e, sobretudo, em Lenin - e que sua peculiaridade no que diz respeito à delimitação das classes sociais em uma determinada formação social é o fato de estar subordinada à análise das práticas sociais.

\footnotetext{
7 método da "leitura sintomal" distingue-se da "leitura imanente". Enquanto esta consistiria em buscar o exato sentido de um conceito, o que verdadeiramente determinado autor quis dizer, a leitura sintomal procura ler não só no que o autor diz, mas o que omite e o que poderia ser dito dentro da problemática teórica que o norteia. Está ligada ao conceito de "ruptura epistemológica", de Gaston Bachelard (1996), e à idéia deste de que é possível - e preciso - fazer uma psicanálise do conhecimento objetivo.

${ }^{8}$ Não é casual o fato de Poulantzas (1977, p.12) enfatizar como uma das características principais do materialismo histórico - além do "primado do ser sobre o pensamento, do real sobre 0 conhecimento que dele se tem" - o fato de "distinguir entre os processos reais e os processos de pensamento, entre o ser e o conhecimento". Devemos ressaltar que este procedimento garante uma constante renovação dos objetos abstrato-formais do marxismo, livrando-os dos limites históricos que sofre toda prática teórica e possibilitando a construção do conhecimento objetivo no campo da ciência da história.
}

${ }^{9}$ Referimo-nos aos trabalhos de Cardoso (1973) e Léger (1976), já citados anteriormente.

Fim da luta de classes? A teoria das Classes em Poder político ... 


\section{DeterminaÇão em “Últtima InSTÂNCIA" E Distinção entre Estruturas e Práticas}

A despeito de Poder politico e classes sociais ser um trabalho complexo e refinado, é sintomática a ausência de uma articulação rigorosa entre 0 desenvolvimento dos conceitos e o método de exposição adotado pelo autor. Há, ao longo da obra, conceitos utilizados e articulados que são desenvolvidos e completados de modo fragmentado. Este é o caso da teoria das classes sociais: não basta ler apenas o segundo capítulo introdutório, intitulado "Política e classes sociais", sem o contextualizar com a perspectiva epistemológica e a proposta metodológica da introdução e com os conceitos de "conjuntura", "força social", "defasagem" e "efeitos pertinentes" - o que remete à relação entre a prática teórica, de um lado, e estruturas e práticas de outro, assim como à própria distinção entre estruturas e práticas.

Se Poulantzas tem uma forte relação com a corrente althusseriana, no que diz respeito ao tema da determinação do econômico, ela é relocalizada de um modo próprio na formulação do conceito geral e abstrato de "modo de produção geral". 0 conceito de materialismo histórico é dividido em três partes: uma "teoria geral", uma "teoria particular" e, como vimos, "teorias regionais", sendo que a primeira corresponde a um axioma, enquanto as outras duas dizem respeito a um tipo de articulação entre níveis de análise diferentes, que vão desde a abstração mais geral à análise empírica - o que só é possível devido à existência do conceito de "defasagem" entre estruturas e entre estruturas e práticas, como mostraremos mais a frente. Antes, vejamos o modo como Poulantzas estrutura o seu processo de pensamento.

0 nível mais geral de análise é a base para entender todo modo de produção: parte-se da pressuposição lógica de que a instância econômica seja a única a apresentar elementos que são invariantes - os trabalhadores, o nãotrabalhador e os meios de produção - mas que só existem na sua combinação variável. Estes elementos se relacionam de duas formas: a) por uma relação de apropriação real entre 0 trabalhador e os meios de produção (ligada ao processo de trabalho), e b) por uma relação de propriedade “[...] que implica a intervenção do não-trabalhador como proprietário, quer dos meios de produção, quer dos meios de trabalho, quer de ambos, e consequentemente do produto" (POULANTZAS, 1977, p. 26). Este é lugar da "determinação em última instância" do econômico, identificado na "teoria geral do materialismo histórico". 
Depende, pois, da combinação - histórica - destas duas relações a forma como se caracterizará um modo de produção particular. Dito de outra maneira, é desse ponto de partida que se pode construir um conceito de análise que é o de "modo de produção particular" (escravista, feudal ou capitalista), identificado por Poulantzas como sendo um objeto abstrato-formal. Como as relações de produção não se apresentam de modo "puro" nas diferentes sociedades - dependendo de uma série de outras relações políticas e ideológicas -, para se trabalhar o conceito de um modo de produção particular, deve-se levar em conta a relação existente entre as três instâncias ${ }^{10}$ : neste nível de análise, predomina a "implicação recíproca" entre as instâncias econômica, política e ideológica.

Ou seja, a determinação do econômico se dá antes da aplicação do conceito (geral) de modo de produção a um período histórico determinado, ao qual corresponde o conceito modo de produção particular. Isto remete uma noção peculiar da determinação em última instância: a determinação do econômico é deslocada da análise das sociedades concretas para a construção do instrumental teórico necessário à análise macro-histórica das práticas sociais. ${ }^{11}$

Respeitando a transposição que há entre os diferentes níveis de análise, podemos afirmar que, para Poulantzas, um modo de produção particular é caracterizado por uma dupla combinação: a combinação das instâncias econômica, política e ideológica levada a cabo por uma análise macro-histórica de uma formação social que, por sua vez, depende da (e se baseia na) combinação entre as relações de apropriação real e as relações de propriedade; combinação esta última que, além de servir de referência à primeira, é a raiz teórica que explica a

\footnotetext{
${ }^{10}$ Embora Poulantzas não defina de forma clara, há uma padronização no uso dos conceitos. Geralmente ele usa o termo "nível" para designar diferentes planos de análise que perpassam desde a abstração "filosófica" até a análise empírica mais rica, como por exemplo "nível do modo de produção geral", "nível do modo de produção particular", "nível da formação social"; usa 0 termo "instância" quando está trabalhando no nível teórico de um modo de produção particular (oras designado por modo de produção "puro"), como a "instância econômica", a "instância política" e a "instância ideológica"; usa o termo "estrutura" quando sua análise "desce" ao nível da formação social, como "estrutura econômica", "estrutura jurídico-política", "estrutura ideológica"; e, por fim, podemos também identificar o termo "práticas sociais" quando desce ao nível da observação empírica.

${ }^{11} 0$ que pode levar a um questionamento acerca de uma possível existência de uma teoria antropológica e de qual seria o seu fundamento. Consideramos, no entanto, que estas questões estão para além do escopo deste trabalho, o que não significa de modo algum a sua desimportância.
} 
transição de um modo de produção a outro. Esta dupla combinação é articulada pela teoria particular do materialismo histórico.

Tendo em mãos o objeto "modo deprodução" de uma etapa macro-histórica, pode-se partir para a análise histórica de uma formação social. Defendemos que Poulantzas (1977, p. 14), manipula o conceito de "formação social" como sendo um segundo nível de abstração e não a realidade empírica propriamente dita. Este é um ponto polêmico, pois embora ele diga que o conceito modo de produção é uma abstração e que os objetos reais concretos correspondem à formação social o modo como ele articula sua teoria das classes depende de que exista um outro nível - propriamente empírico - associado por ele mesmo ao conceito de "Sociedade" (p. 46-66) - e, de modo subseqüente, também aos conceitos de "conjuntura" e de "força social" (p. 90; 107). A formação social é, assim, uma "superposição de vários modos de produção "puros"” - Poulantzas atribui esta afirmação a Lenin - em que predomina um todo estruturado com a dominância de um modo de produção e na qual se podem identificar as estruturas "estruturantes" das práticas sociais. A sociedade é, por sua vez, o lugar onde se encontram as relações sociais em seu "estado bruto" que é o objeto primeiro do materialismo histórico; esse é 0 nível das práticas sociais dos "agentes-suportes" e das instituições propriamente ditas. A articulação entre estes dois níveis de análise corresponde à tarefa da teoria regional do materialismo histórico, daí a preocupação insistente de Poulantzas em diferenciar "estruturas" de "práticas".

A diferenciação entre estruturas e práticas é momento para onde convergem a perspectiva epistemológica e proposta metodológica de Poulantzas. É preciso distinguir a referida diferença enquanto "dois sistemas de relações" que recobrem "domínios diferentes". Para Poulantzas (1977, p. 84), "[...] uma instância estrutural nem por isso constitui diretamente uma prática: trata-se de dois sistemas - ou série de relações reguladas - particulares, possuindo as suas características próprias, mas cuja relação é entre estruturas e práticas estruturadas relativas a estas estruturas". É importante reter essa noção de que as práticas são "estruturadas" pelas estruturas enquanto afirmação epistemológica. Ou seja, as práticas sociais, embora possam ser observadas enquanto tais, só podem ser entendidas no universo das práticas de classe, caso contrário, cair-se-ia numa perspectiva empiricista, atribuindo-se aos agentes-suportes o caráter de indivíduossujeitos - problemática essa identificada em Poder político e classes sociais como 
"historicista""12. A não compreensão dessa distinção, nestas condições específicas, implicaria uma contradição na obra de Poulantzas: confundir-se-iam estruturas com instituições ou classes sociais com agentes-suportes (enquanto indivíduos), o que poderia levar a se questionar o papel das estruturas na formação das classes sociais ou, de modo inverso, a questionar uma suposta existência "fixa" das estruturas e a impossibilidade de se mudá-las. ${ }^{13}$

Para Poulantzas (1977, p. 86), essa "não distinção das estruturas e das práticas" pode ocasionar uma grave conseqüência que é considerar o econômico “como estrutura sobre a qual teria ‘agido' a luta de classes, instalada unicamente nos níveis político e ideológico". Se insistimos neste ponto é porque ele tem uma importância cardeal no procedimento metodológico que Poulantzas está apresentando. Se no nível da teoria particular do materialismo histórico - a que trata da relação entre o conceito modo de produção e a formação social - há uma relação de implicação recíproca entre as instâncias econômica, política e ideológica, no nível da teoria regional - da relação entre o conceito de formação social e as práticas sociais - a relação que prevalece é a da "autonomia relativa" entre as estruturas. Seria a existência de uma autonomia relativa que possibilitaria avançar para as teorias regionais: Marx teria feito a teoria regional do econômico n'O Capital, Poulantzas pretende avançar a teoria regional do político. Mas há ainda aqui uma contradição aparente, ${ }^{14}$ que nos obriga a avançar sobre esse conceito de "autonomia relativa".

Não devemos esquecer que a pretensão central de Poder político e classes sociais é avançar a teoria regional do político no modo de produção capitalista - principalmente na segunda, terceira e quarta parte do livro. Portanto, Poulantzas observa - e "teoriza" - a relação entre as estruturas e as práticas sociais do ponto de vista de um momento de coesão social, especificamente, do modo de produção capitalista. 0 conceito de "autonomia relativa" da forma como é usado para tratar a relação entre as estruturas e as práticas está, assim, atrelado a um momento historicamente determinado, que é sempre provisório e que está associado por Poulantzas (1977, p. 48) ao conceito de "político" e à concepção ampliada do Estado como "[...] organização para a manutenção das condições da produção e,

\footnotetext{
${ }^{12}$ Ver páginas 36, 58, 84-86, 123.

${ }^{13}$ Esta observação é pertinente, pois Poulantzas por vezes designa o nível das práticas sociais como sendo o das "práticas de classes", podendo levar à confusão assinalada.

${ }^{14}$ Referimo-nos aqui às críticas de Saes (1998), apresentadas anteriormente.
}

Fim da luta de classes? A teoria das Classes em Poder político ... 
assim, das condições de existência e do funcionamento da unidade de um modo de produção e de uma formação [isto é, do que caracterizamos como sendo uma dupla combinação]".

Mas Poulantzas (1977, p.86, 151-152) não se restringe a trabalhar apenas no nível da teoria regional do político no modo de produção capitalista. Há, na primeira parte do livro e no capítulo três da segunda parte, um tratamento teórico acerca da passagem de um momento de coesão a outro, de um modo de produção a outro - o que implica a relação entre as estruturas, assim como estão explicitadas também as condições da relação entre estruturas e práticas. É exatamente aqui que se insere um conceito-chave para o funcionamento (e para a própria existência) da teoria regional e sua relação com a teoria particular: 0 conceito utilizado por Poulantzas (que indica a possibilidade de existência) de "defasagens" (décalage) entre estruturas e entre estruturas e práticas. Explicitemos melhor: quando no estudo de uma determinada sociedade viermos a processar a articulação entre as estruturas econômicas, políticas e ideológicas dominantes (que são conceitos abstrato-formais) ou viermos a realizar a articulação entre os conceitos e a realidade empírica (composta pelos objetos reais-concretos), podem ocorrer defasagens entre esses diferentes elementos.

Por exemplo, no que diz respeito à existência de defasagens entre as estruturas dominantes de uma formação social, pode existir uma situação de defasagem das estruturas políticas e/ou ideológicas dominantes com relação à estrutura econômica dominante, o que pode significar uma situação de transição. Este é o caso do Estado Absolutista, caracterizado por Poulantzas (1977, p. 154-156) como um "Estado de transição": havia uma não-correspondência da estrutura jurídico-política dominante - que garantia um tipo de relações de propriedade específico - com relação à estrutura econômica dominante, marcada pela manufatura - que era caracterizada por um tipo de relação de apropriação real. Existia, nesse caso, uma defasagem entre a relação de propriedade e a relação de apropriação real dos meios de produção. Já no que diz respeito ao segundo tipo de defasagem - e o que nos interessa aqui diretamente -, entre os conceitos e a realidade empírica, podem ocorrer relações de defasagens entre as práticas política, econômica e ideológica de uma mesma classe social. Para essa situação, Poulantzas dá o exemplo de Lênin que, em 0 que fazer?, falava da "necessidade de dar à própria luta econômica um caráter político" (p. 88); ou seja, a prática política de uma classe não resultava espontaneamente da sua prática econômica (no caso, a luta sindical), sendo necessário uma organização político-ideológica 
(o partido) para dar um caráter de classe - homogêneo - às práticas dos agentessuportes que se encontravam na situação de classe operária naquela formação social. Voltaremos a este ponto no tópico abaixo. Por ora, resta dizer que, levada às últimas conseqüências, essa formulação de Poulantzas acaba por relativizar o papel da prática teórica na construção do conhecimento objetivo, condicionando este sempre às determinações da realidade objetiva. No caso específico tratado aqui, as práticas sociais assumirão um lugar especial na articulação dos conceitos, assim como na sua rearticulação (para os casos de possível transição).

\section{Das Práticas às Classes Sociais}

Nas condições explicitadas acima, defendemos que o método de Poulantzas (1977, p. 86-87), usado para delimitar as classes sociais numa dada formação social, pretende partir primeiro das práticas sociais para - depois de uma mediação teórica específica - chegar às classes sociais. Poulantzas escreve que, devido à existência de um "desenvolvimento desigual" - e combinado, acrescentaríamos - entre as estruturas, marcado por relações de defasagens, haveria igualmente defasagens entre as práticas das classes, na medida em que, por sua vez, estas constituiriam um sistema estruturado, refletindo as relações das estruturas sobre os agentes-suportes.

A idéia geral de modo de produção, aplicada a uma determinada sociedade, pressupõe que existam relações de exploração nas relações de produção, o que significa a existência de conflitos em toda sociedade de classes. No entanto, as relações deprodução numadeterminadasociedade porsi só não engendram práticas contraditórias que ameacem a reprodução do sistema, estas dependem também dos efeitos das estruturas política e ideológica, como mostramos acima. Assim, o surgimento das classes sociais enquanto conjunto social com uma prática política homogênea (isto é, sem defasagens) ocorrerá numa formação social somente em um momento de iminência revolucionária, ou seja, num momento em que os elementos que garantem a coesão da unidade social se encontrarem ameaçados. Fora dessa condição, as classes só podem ser localizadas por mediações teóricas específicas cujas referências são as estruturas que determinam a dupla combinação dominante de uma formação social. É neste sentido que Poulantzas confere à estrutura jurídico-política - "poder institucionalizado do Estado" no nível da formação social e "conjunto de instituições" no nível das práticas - esse papel de mediação por meio da relação com o que ele denomina 
de "efeitos pertinentes": é preciso ver em que medida a presença de interesses específicos de alguns grupos sociais (vistos a partir das relações de produção) em uma conjuntura política constituem ou não um elemento novo, que induz seja à rearticulação das estruturas, seja à possibilidade de surgimento de uma efetiva contradição face à dupla combinação que caracteriza a dominação - e conseqüentemente a reprodução - de um modo de produção. ${ }^{15}$ E aqui constatamos a forte influência sobre Poulanzas que exerce Lenin por meio do papel que atribui ao Estado nas sociedades de classes.

É, pois, partindo desta posição teórica que, ao caracterizar o modo de produção capitalista, Poulantzas fala de "bloco no poder" como sendo a unidade de diferentes interesses das "frações da burguesia" sem que isso implique a existência de conflitos no interior da classe dominante. Pode-se legitimamente imputar a esse conceito de bloco no poder - associado à existência da estrutura jurídico-política capitalista - 0 sentido de prática política material da burguesia enquanto "classe virtual", ou seja, como uma classe social que existe apenas de modo predeterminado na medida em que possui todas as condições essenciais à sua realização; fato este que justificaria a existência de diferentes interesses entre as frações, assim como a autonomia relativa do Estado face a alguns desses interesses sem que exista a ruptura da unidade do bloco no poder. Por outro lado, no que diz respeito à classe explorada - e dominada política e ideologicamente - parece que o conceito de "classe em potência", cunhado por Boito (2003), ocupa uma justa posição dentro da problemática das classes em Poder político e classes sociais: a formação da "classe dominada", em condições normais de funcionamento de um modo de produção, é apenas uma "possibilidade real" e que para se tornar uma "classe ativa" depende da "[...] combinação de inúmeros fatores de ordem econômica, política e ideológica” (BOIT0, 2003, p. 243-245).

Precisemos melhor a formulação geral: numa situação de equilíbrio provisório da totalidade social, caracterizada pela dominância de um modo de produção em uma determinada formação social concreta, o balanço geral da ação política dos agentes-suportes convergirá no sentido da reprodução das estruturas que garantem o funcionamento da totalidade social - mantendose a dupla combinação que caracteriza essa totalidade -, podendo-se apenas determinar nesse nível de análise a existência de classes seja em estado virtual ou em potência, como no caso da burguesia e da classe operária, respectivamente.

\footnotetext{
${ }^{15}$ Sobre o conceito de efeitos pertinentes ver Poulantzas (1977, p. 76, 94).
} 
De modo inverso, somente numa situação de ação "aberta ou declarada" da luta de classes - característica de um período iminente de transição, por meio da existência de classes organizadas colocando em questão a estrutura jurídicopolítica "dominante" e a dupla combinação - é que se tem a presença real das classes sociais e que a prática política dessas classes em conflito aberto passa a configurar-se também numa estrutura para a prática política das outras classes presentes na formação social.

Isto indica que nos períodos nos quais não há uma ação aberta ou declarada das classes sociais podem ocorrer, como já adiantado acima, defasagens entre as diferentes práticas econômicas, políticas e ideológicas das classes sociais, obrigando-nos a trabalhar com conceitos mais próximos das práticas sociais. ${ }^{16}$

Os conceitos de classe virtual ou em potência residem num nível teórico específico que é o da teoria particular do materialismo histórico, caracterizada pela dominância do modo de produção capitalista. Quando descemos ao nível da teoria regional, à análise das práticas sociais em um momento de coesão social, no qual a "luta" se encontra em estado velado - isto é, pela existência de conflitos que não se caracterizam enquanto contradições - deve-se priorizar na análise as práticas dos agentes-suportes na conjuntura política e ver como constituem "forças sociais" ${ }^{17}$ Isto é necessário porque, para Poulantzas (1977, p. 94), há uma "indeterminação" no nível das práticas sociais que depende da "ação combinada das forças sociais". É neste sentido que ele cria outros recursos conceituais a partir da relação das práticas com a referência da dupla combinação que caracteriza 0 índice de dominância em uma formação social específica:

a) seja das práticas em relação às relações de produção (dominantes ou não): "frações de classe", "frações autônomas" e "classes distintas";

\footnotetext{
${ }^{16} 0$ que não nos aproxima do conceito de "posição contraditória de classes", de Eric Olin Wright (1981). Se Poulantzas parte das práticas sociais para chegar às classes, o esquema de Wright pretende atribuir às diferentes práticas que não se encaixem no esquema conceitual das classes (definidas somente a partir das relações de produção do modo de produção dominante) como sendo práticas com um caráter "contraditório". Neste sentido, seria interessante uma pesquisa teórica diferenciando os conceitos de "situação contraditória" de Wright com o de "defasagem" de Poulantzas, que, ao que parece, remetem a uma perspectiva diferenciada no que diz respeito à relação entre ciência (teoria) e realidade objetiva.

${ }^{17} \mathrm{E}$ isto se aplica tanto às classes principais do modo de produção dominante da formação social como também às classes sociais características de outros modos de produção, que devido à combinação das diferentes estruturas (dominantes e não dominantes) não se apresentam de modo efetivo como tais.
} 
b) seja das práticas em relação a uma estrutura do modo de produção dominante: é o caso das "categorias sociais", como por exemplo a burocracia em relação à estrutura jurídico-política ou os "intelectuais" com relação à estrutura ideológica;

c) ou seja das práticas em relação aos dos efeitos - secundários - gerados pela combinação das estruturas dominantes com estruturas nãodominantes ${ }^{18}$ sobre as classes, as categorias e as frações: que corresponde à existência das "camadas sociais", cujos exemplos dados por Poulantzas (1977, p. 81-82) são a "aristocracia operária” e as “"cúpulas' da burocracia e da administração".

É preciso distinguir, no entanto, dois tipos de campos de atuação das forças sociais numa conjuntura que estão presentes em Poder político e classes sociais: o de ruptura com as condições políticas dominantes que limitam a sua prática política - colocadas pelo conjunto das estruturas dominantes e garantidas pela estrutura jurídico-política -, que seria o da ação das frações autônomas; e o de rearticulação das estruturas (defasadas entre si) dentro dos limites "estruturais" do modo de produção dominante sem tocar no núcleo da estrutura jurídico-política, que é o caso da ação das "classes distintas" (e também pode ser das categorias sociais). É necessária essa distinção porque, para Poulantzas (1977, p. 82, 90), só as frações de classe, as classes distintas e as categorias sociais poderiam constituir forças sociais por meio dos efeitos pertinentes percebidos na conjuntura. Contudo, é necessário especular sobre a impossibilidade de participação das camadas sociais como força social e o modo como Poulantzas trabalha isto teoricamente; que implicações a aceitação de tal possibilidade traria para a sua teoria das classes? Vejamos como ele trata a questão:

A propósito da distinção entre camadas e frações, ela é sobretudo pertinente no que concerne ao seu reflexo a nível político: as frações, na medida em que se tornam autônomas, são suscetíveis, ao contrário das camadas, de se constituírem em forças sociais. Isto de maneira nenhuma significa que a distinção frações-camadas recubra exatamente a dos efeitos respectivos do

\footnotetext{
${ }^{18} 0$ termo usado por Poulantzas (1977, p. 82) é "efeitos secundários da combinação dos modos de produção em uma formação social". Utilizamos o conceito "estruturas não-dominantes" para reforçar a idéia presente em Poulantzas de que uma formação social é composta por várias estruturas - além das estruturas do modo de produção dominante - que estão subdeterminadas pelas estruturas dominantes, mas que não deixam de existir nem muito menos de se combinar, dentro de certos limites, com estas.
} 
econômico e do político-ideológico. [...] Além disso, conviria não pensar que a localização de camadas - distintas das frações - implica um hiperempirismo acadêmico "estratificado". Ela é importante, na medida em que designa como produtos dos efeitos secundários da combinação dos modos de produção, certas franjas-limites das classes, categorias e frações que podem, sem serem forças sociais, influir na prática política daquelas. É por exemplo o caso da "aristocracia operária" que Lenin designa em 0 Imperialismo... como camada social: ela não pode, em virtude do seu caráter de franja intermediária, constituir uma força social, mas influir na prática política da classe operária, funcionando politicamente como "agente" operário da burguesia. (POULANTZAS, 1977, p. 83 - grifos do autor).

Seguindo a lógica do pensamento de Poulantzas, as classes podem ser percebidas no nível da formação social seja por meio de uma "ação aberta" (característica de um período de transição) ou por meio dos "efeitos pertinentes" (em uma situação de estabilidade da coesão social). Vimos que isto ocorre porque a formação social é resultado da combinação de vários modos de produção com a dominância de um deles; os modos de produção não dominantes, embora não possam ser localizados em "estado puro", estão presentes na formação social por meio de variadas estruturas econômicas, políticas e ideológicas que são constantemente sobredeterminadas pelas estruturas do modo de produção dominante. Como se pode observar na citação acima, Poulantzas caracteriza a impossibilidade de constituição das camadas sociais como forças sociais devido ao seu caráter de "franja intermediária" que surge a partir dos efeitos secundários da combinação das estruturas não dominantes com as estruturas do modo de produção dominante. Cabe questionar: por que esses efeitos possuem um caráter "secundário"? A essa pergunta segue uma outra indagação: poderia a combinação das estruturas gerar um efeito primário? E qual seria o resultado?

Neste sentido, parece que existeem Poderpolítico e classes sociais um esforço de pensar o Estado capitalista e a sua dinâmica de funcionamento principalmente a partir da transição do feudalismo. Podemos ver que os exemplos citados de camadas sociais remetem diretamente a uma espécie de "resíduo estrutural" do modo de produção feudal - "aristocracia" operária, "cúpulas" da burocracia e da administração - agindo na referida dinâmica. Pode-se afirmar, assim, que Poulantzas está pensando na articulação das estruturas do modo de produção feudal com as estruturas dominantes do modo de produção capitalista. ${ }^{19}$

19 "Conhecemos as grandes linhas deste processo de sobredeterminação, pelas classes do modo de

Fim da luta de classes? A teoria das classes em Poder político ... 
No entanto, se há em Poulantzas uma orientação de partir das práticas sociais para chegar às classes sociais - como procuramos mostrar acima e como atesta a sua preocupação em pensar a ação de grupos sociais distintos das classes, frações e categorias sem cair num "hiper-empirismo acadêmico "estratificado"” -, é possível dizer que não há uma tipificação "rígida" das camadas sociais numa determinada formação social. Logo, é possível trabalhar com outras determinações estruturais das ações coletivas, seja de ordem cultural, simbólica, etc. sem perder de vista a centralidade da teoria das classes sociais para o entendimento das diferentes sociedades. Nesse sentido - e nessas condições -, é possível haver uma aproximação do marxismo com as análises da sociologia da estratificação social. Isto pode ser ilustrado a partir da formação social brasileira: as questões de gênero e "racial" exercem pressão no sentido de um fracionamento no interior da classe operária, conduzindo ao surgimento de camadas, por exemplo, no seio da própria classe operária; apesar de também ser explorado, o operário homem e branco vive condições de opressão bem diferentes - e mais razoáveis - do que a operária mulher e negra.

Já no que diz respeito ao tema da transição, uma vez que a determinação em última instância do elemento econômico foi deslocada das práticas sociais para o conceito geral e abstrato de modo de produção e a história deixou de ser um processo linear para ser uma "evolução" de "possibilidades estruturais" - marcada pela indeterminação da conjuntura (POULANTZAS, 1977, p. 94) -, torna-se necessário uma análise concreta das práticas sociais para tentar desvendar essas possibilidades que poderiam convergir em outra organização social, coesa a partir da dominância de um outro modo de produção. Dessa perspectiva, se o socialismo passa a ser uma possibilidade estrutural, deixa de ser uma inevitabilidade histórica. Do mesmo modo, também se abre a possibilidade de transição do capitalismo para modos de produção outros que não os já conhecidos historicamente. É possível, então, que possam resultar da combinação das diferentes estruturas de uma formação social efeitos não somente secundários como também "primários";

produção dominante, das classes dos modos de produção dominados em uma formação social. Este processo depende das formas concretas desta dominância: transformação da nobreza feudal em fração da burguesia - capitalização da renda fundiária -, dos pequenos-burgueses - camponeses, artesãos - em frações, quer da burguesia - pequenos capitalistas - quer da classe operária, camponeses parcelares em operários assalariados; enfim, de toda a gama de decomposição das classes subdeterminadas e da resistência a esta decomposição, que comanda precisamente a existência ou não de uma classe ou fração enquanto força social, enquanto classe distinta ou fração autônoma" (POULANTZAS, 1977, p. 80). 
efeitos que teriam um impacto na constituição das forças sociais, capazes de alterar o equilíbrio de determinada coesão social. De acordo com a lógica da teoria das classes em Poder político e classes sociais, é possível pensar na possibilidade de uma determinada camada social se transformar seja em classe distinta seja em fração autônoma e, por meio dos efeitos pertinentes, alterar qualitativamente a relação entre as estruturas - o que poderia resultar em uma nova forma de Estado, no caso de manutenção das relações de produção capitalista, ou em um outro tipo de Estado, no caso de uma ruptura com as relações de produção dominantes caracterizando a transição de um modo de produção a outro.

\section{À Guisa de Conclusão}

Há um processo em curso no século XX, de avanço dos questionamentos no interior de algumas influentes análises sociológicas acerca da centralidade das classes sociais para a explicação social. Vimos que surge, num primeiro momento, uma ruptura com a até então predominante centralidade histórica das classes sociais para a compreensão histórica. Com o surgimento de novos atores sociais não operários reivindicativos em cena no Maio de 1968, há uma revisão no âmbito das análises sociológicas no sentido de inviabilizar qualquer possibilidade de centralidade teórica das classes sociais para se entender os diferentes grupos sociais e ações coletivas.

A partir de algumas dessas polêmicas suscitadas pelo Maio de 1968, procuramos então demonstrar que é possível uma análise de determinados grupos sociais dentro da perspectiva marxista - baseada na centralidade teórica das classes sociais - sem cair no que muitos caracterizaram como sendo uma espécie de determinismo ortodoxo da economia no âmbito das práticas sociais e podendo contemplar outras esferas da vida social como as questões de ordem simbólicas e culturais.

A partir de uma concepção de que o marxismo não é uma disciplina hermeticamente acabada e que vem passando, desde meados do século XX, por um processo de renovação, procuramos contextualizar as contribuições de Nicos Poulantzas, em especial sua obra Poder político e classes sociais, com os avanços e limites desse processo no interior da corrente althusseriana.

Defendemos que o autor retém dessa corrente, principalmente mas não exclusivamente, o primado da prática sobre a teoria. Essa concepção se 
materializaria na teoria das classes sociais que está presente em estado prático na sua obra. Tratamos, então, de enunciar os elementos dessa teoria, mostrando que os conceitos abstrato-formais situados nos diferentes níveis teóricos - principalmente o conceito de estrutura e excetuando o conceito "modo de produção geral" - devem sempre ser interpretados de acordo com as práticas sociais e, em casos extremos, devem ser rearticulados.

Dessa forma, há na organização do sistema conceitual de Poulantzas, uma relação de complementaridade entre os conceitos de "conjuntura" e "força social", situados no nível das práticas sociais, e os conceitos de "defasagem" e "efeitos pertinentes" localizados no nível do modo de produção. Com isso, é possível trabalhar a relação entre o conceito de classe social - sem que ele implique mecanicamente as práticas econômica, política e ideológica homogêneas de classe - e a delimitação das classes em uma determinada formação social. Vimos também que Poulantzas procura sistematizar outros conceitos como os de "frações de classe", "categoria social" e "camada social" que assumem um papel de "conceitos auxiliares" mais próximos das práticas sociais, cuja função é a de construir uma ponte entre estas e o conceito de classe.

\section{REFERÊNCIAS}

ALTHUSSER, Louis. La revolución teórica de Marx. Buenos Aires: Siglo XXI, 1974.

ALTHUSSER, Louis; BALIBAR, Étienne. Lire le Capital. Paris: Maspero, 1971. 2 v. BACHELARD, Gaston. A formação do espirito científico: contribuição para uma psicanálise do conhecimento. Rio de Janeiro: Contraponto, 1996.

BELL, Daniel. 0 advento da sociedade pós-industrial: uma tentativa de previsão social. São Paulo: Cultrix, 1977.

BOITO, Armando. A (difícil) formação da classe operária. In: et alii.

Marxismo e ciências humanas. São Paulo: Xamã, 2003.

CARDOSO, Fernando H. Althusserianismo ou marxismo? A propósito do conceito de classes em Poulantzas: comentários. Estudos Cebrap, São Paulo, n. 3, p. 65-85, jan. 1973. 
FRASER, Nancy. Da redistribuição ao reconhecimento? Dilemas da justiça na era pós-socialista. In: SOUZA, Jessé (Org.). Democracia hoje: novos desafios para a teoria democrática contemporânea. Brasília: Ed. da UNB, 2001.

HIRANO, Sedi. Castas, estamentos e classes sociais. São Paulo: Alfa Omega, 1973 .

HONNETH, Axel. Luta por reconhecimento: a gramática moral dos conflitos sociais. São Paulo: Ed. 34, 2003.

LEGER, Danièle. Pour une sociologie marxiste du politique: itinéraire de Nicos Poulantzas. Revue Française de Sociologie, v. 17, n. 3, jul.-set., 1976.

LOCKW00D, David. El trabajador de la clase media: un estúdio sobre la conciencia de clase. Madrid: Aguilar, 1962.

MARX, Karl; ENGELS, Friedrich. A ideologia alemã. São Paulo: Martins Fontes, 1998.

MATOS, Olgaria C. F. Tardes de Maio. In: SHERER, Amanda Eloina; NUSSBAUMER, Gisele; FANTI, Maria da Gloria di (Org.). Utopias $\&$ Distopoas: 30 anos de maio de 68. Santa Maria: UFSM, 1999.

MILLS, Wright. A nova classe média. Rio de Janeiro: Zahar, 1979.

POULANTZAS, Nicos. Poder político e classes sociais. São Paulo: Martins Fontes, 1977.

RUMIANTSEV, Alexei. La estructura de la Clase Obrera de los Países Capitalistas. Praga: Paz y Socialismo, 1963.

SAES, Décio. Marxismo e história. Crítica Marxista, São Paulo, v.1, p. 39-59, 1994.

. A questão da autonomia relativa do Estado em Poulantzas. Crítica Marxista, São Paulo, v.7, p. 46-66, 1998.

TOURAINE, Alain. La sociedad post-industrial. Barcelona: Ariel, 1971.

WRIGHT, Eric Olin. Classe, crise e Estado. Rio de Janeiro: Zahar, 1981. 